\title{
LA ESTÉtICA TAOÍSTA EN LA CASA DE FISAC EN CERRO DEL AIRE
}

\author{
Sonia Vázquez-Díaz y Luis Suárez Mansilla
}

Taotist Aesthetics in Fisac's House located in Cerro del Aire, Madrid

Boletín Académico. Revista de investigación y arquitectura contemporánea Escuela Técnica Superior de Arquitectura. Universidade da Coruña elSSN 2173-6723

www.boletinacademico.com

Número 4 (2014)

Páginas 43-52

Fecha de recepción 31.10.2013

Fecha de aceptación 21.01.2014

https://doi.org/10.17979/bac.2014.4.0.1008

\begin{abstract}
Resumen
Reiteradamente se ha referenciado la influencia que la arquitectura oriental ha tenido sobre la obra de Fisac. En este artículo se profundiza sobre ello, buscando huellas de la estética taoísta en la materialización del patio de su casa en Cerro del Aire, que se va transformando a lo largo del tiempo. A través del análisis perceptivo de los elementos que lo conforman - vegetación, un conjunto de rocas y un estanquese descubre cómo Fisac los emplea para evidenciar los principios taoístas: empatía, ritmo vital, reticencia y vacío.
\end{abstract}

\begin{abstract}
Influence of Eastern architecture on Fisac's work has been reiteratedly stated. The aim of this paper is to take a deeper look into this permeation, searching for evidence of the use of Taoist Aesthetics in the courtyard of his house in Cerro del Aire, which has been remodeled over time. The elements of the courtyard — plants, stones and a pond - are perceptually analysed; it is shown how Fisac uses them to materialize Tao Principles: Empathy, Life pace, Reluctance and Emptiness.
\end{abstract}

\section{Palabras clave}

Arquitectura oriental, principios estéticos taoístas, patio, Fisac, casa

\section{Keywords}

Eastern architecture, taoist aesthetic principles, courtyard, Fisac, house 


\section{INTRODUCCIÓN}

Miguel Fisac construye su propia casa en 1956 en Cerro del Aire (Alcobendas, Madrid) ${ }^{1}$; a lo largo del tiempo, la casa va creciendo alrededor de un patio que contiene un estanque de bordes irregulares, dibujados por un conjunto de rocas. Tras las sucesivas ampliaciones, el patio se transforma, retirando los paramentos de vidrio que lo limitaban y protegiéndolo cenitalmente con un lucernario, hasta incorporarlo totalmente al interior (Fig. 01).

Muchos autores han puesto de relieve la profunda huella que la arquitectura oriental, experimentada y admirada por el propio autor en sus viajes, dejó impresa en su obra ${ }^{2}$. El influjo es tan determinante para él, que parafrasea a Lao-Tse cuando define la arquitectura como un trozo de aire humanizado ${ }^{3}$. Su propia casa responde fielmente a esta concepción; Lorente Ayala señala como muestra del rastro japonés la configuración espacial de la vivienda, el empleo de materiales naturales y la disposición en el entorno ${ }^{4}$ (Fig. 02). Por su parte, Arqués Soler apunta sobre ella: «[Es] una vivienda que tanto nos recuerda la palabra japonesa katei, hogar, palabra que se escribe con los signos ortográficos $k a$ (casa) y tei (jardín), indicativo de la relación indisociable entre ambos en la mentalidad japonesa y en la arquitectura de Fisac» ${ }^{5}$.

Sin embargo, no se ha llegado a explicitar la forma concreta en la que esta influencia se materializa en la casa $^{6}$; la arquitectura oriental se encuentra profundamente enraizada en el taoísmo, y comparte con otras disciplinas artísticas unos principios estéticos que subyacen en sus materializaciones. Luis Racionero acota estos principios estéticos, que define como empatía, ritmo vital, reticencia y vacío, y que se describen a continuación ${ }^{7}$.

Mediante la empatía, el arte oriental busca conseguir que el espectador se identifique con lo observado. El perceptor se siente identificado en algún aspecto de lo contemplado, y comprende su implicación íntima con todo lo que le rodea: la ilusión de individualidad se desvanece y descubre la no-dualidad que rige el universo, en el que todo está profundamente interrelacionado ${ }^{8}$. Lo que parecían realidades separadas y antagónicas comparten la misma esencia ontológica y solo se distinguen en grado o apariencia.

El ritmo vital es la energía que mantiene la naturaleza en equilibrio pero en constante transformación. Se transmite evidenciando la fugacidad del instante presente y el permanente cambio en el que está inmerso todo lo existente, así como la tensión inherente a la vida, en la que nada es estático.

La reticencia es la sutileza con la que se manifiesta la esencia del universo; la no-dualidad y el ritmo vital subyacen bajo lo aparente, y por ello no se pueden percibir de forma directa. La estética taoísta, a través de la reticencia, del decir sin decir, apunta hacia estas realidades profundas y esquivas, poniendo el énfasis en lo que se calla para desvelar el misterio del mundo.

El vacío es el espacio que se desocupa para otorgarlo a lo inefable. Del mismo modo que se necesita del silencio para poner en valor el sonido, o que la suma de todos los colores engendra el blanco, el vacío sustenta las formas y les permite ser. La estética taoísta trata de esbozar el vacío como receptáculo de lo contingente.

El propósito de este artículo es indagar cómo se manifiestan los principios de la estética taoísta, de los que Fisac se embebió en sus viajes a Oriente, en el patio de su casa en Cerro del Aire; para ello, se analizan pormenorizadamente sus elementos arquitectónicos en clave fenomenológica, estudiando las percepciones que producen en el habitante?

\section{EL PATIO COMO GERMEN AGLUTINADOR}

Toda la casa se desarrolla en torno al vacío del patio, que actúa como un germen espacial desde el que surgen los muros de mampostería. Éstos acotan las distintas estancias, que gravitan alrededor del patio siguiendo un patrón de asimetría armónica, tan característica del taoísmo: «la verdadera belleza solamente llega a descubrirla aquél que mentalmente completa lo incompleto» ${ }^{10}$.

En la primera fase, el patio no llega a clausurarse, sino que los volúmenes de la casa se articulan para acoger un fragmento de naturaleza; el equilibrio entre casa y entorno es tan delicado que ambos se intersecan sin imponerse jerárquicamente. La primera ampliación termina de abrazar el vacío y el patio se interioriza por completo: el cuarto de juegos se encaja en el lado libre y se asoma también al vacío interior. Mediante una estudiada disposición de los huecos y el machón de la esquina que acoge la chimenea, comedor, estar y cuarto de juegos se vinculan visualmente al patio, pero éste actúa como un nudo, entrelazando espacialmente los diferentes ámbitos pero manteniendo su intimidad al impedir las visiones cruzadas entre ellos (Fig. 03). 

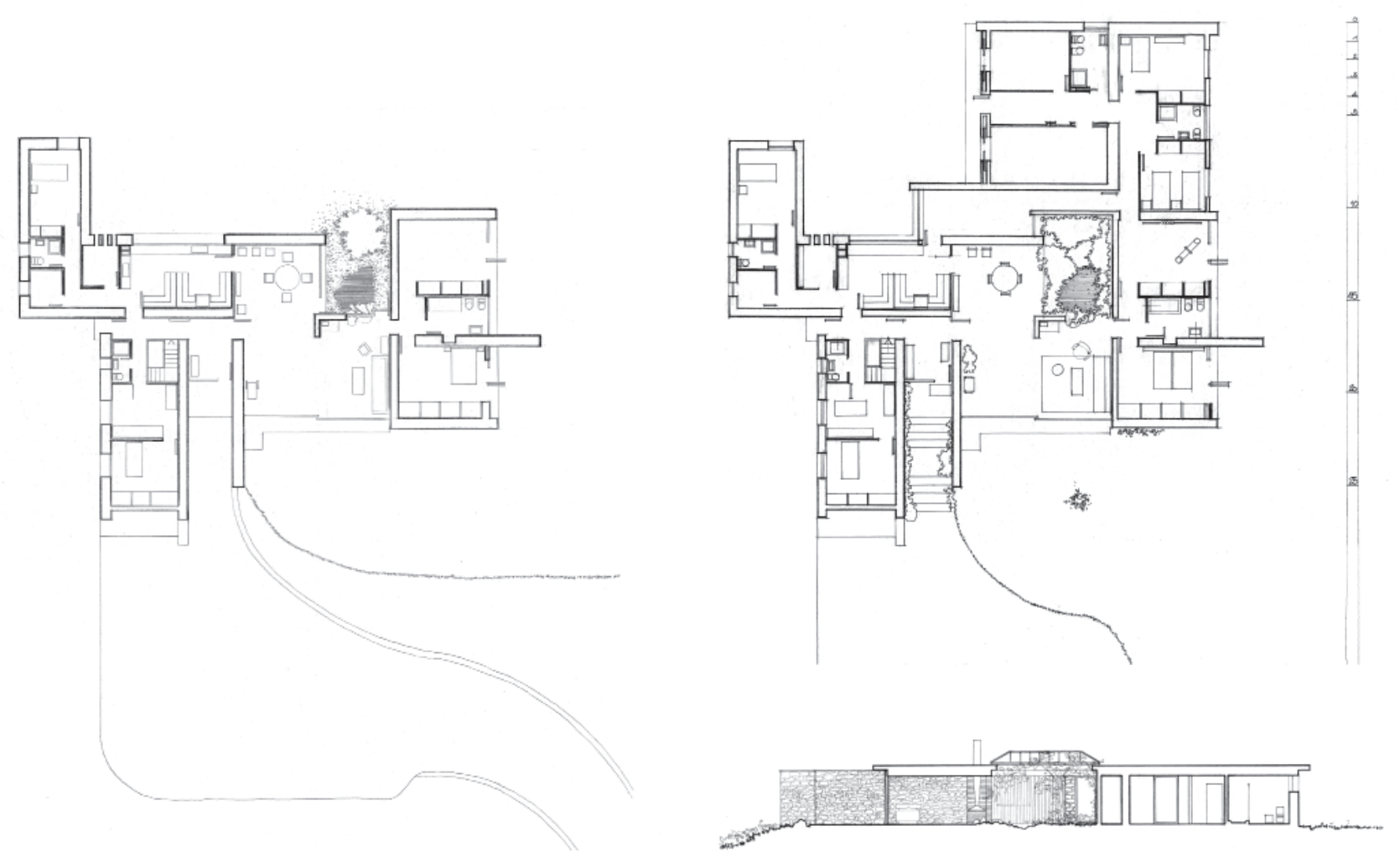

01 Planta de la primera fase, y planta e interpretación de la sección de la tercera fase de la casa en Cerro del Aire.

02 Vista del exterior de la casa desde el acceso.

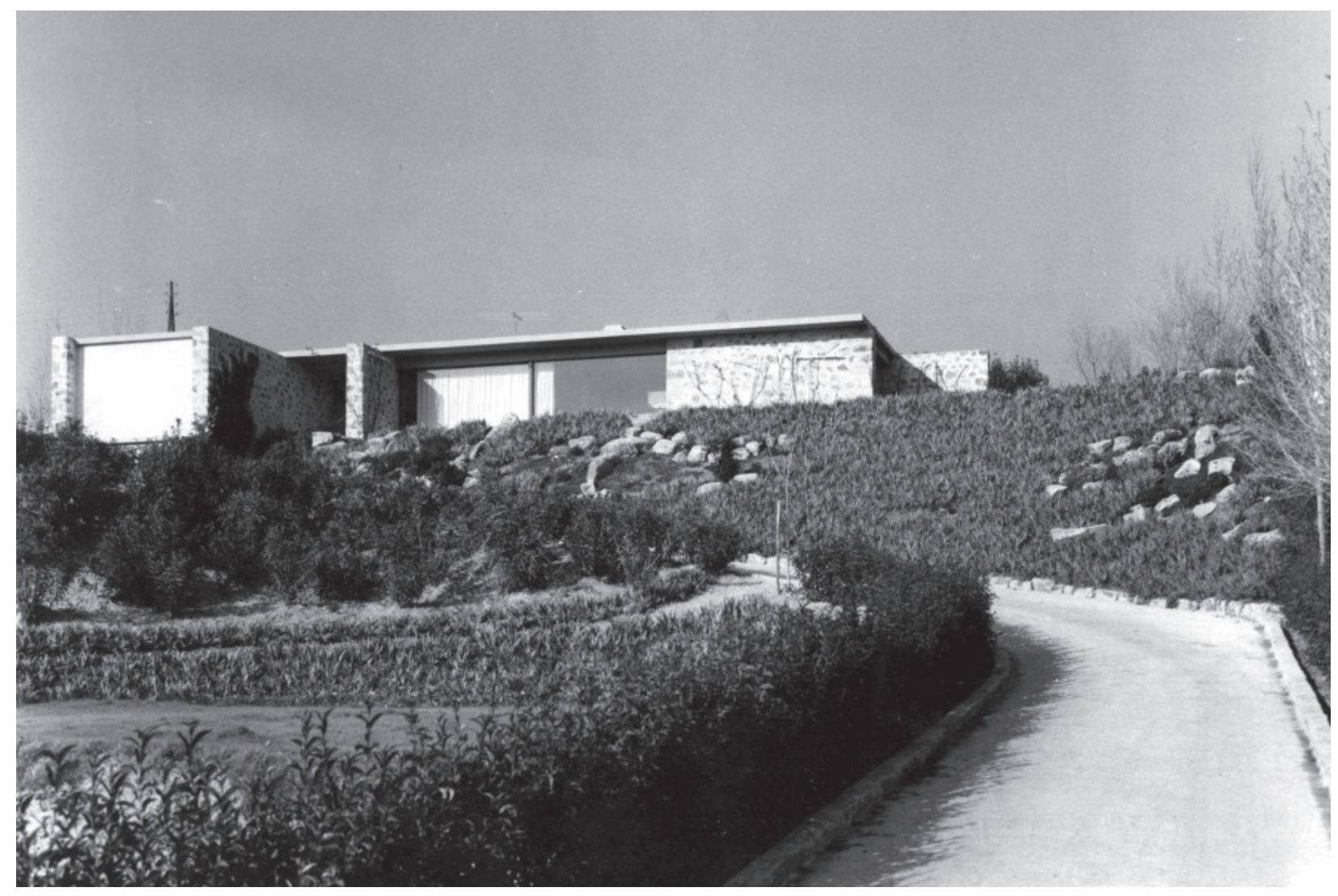




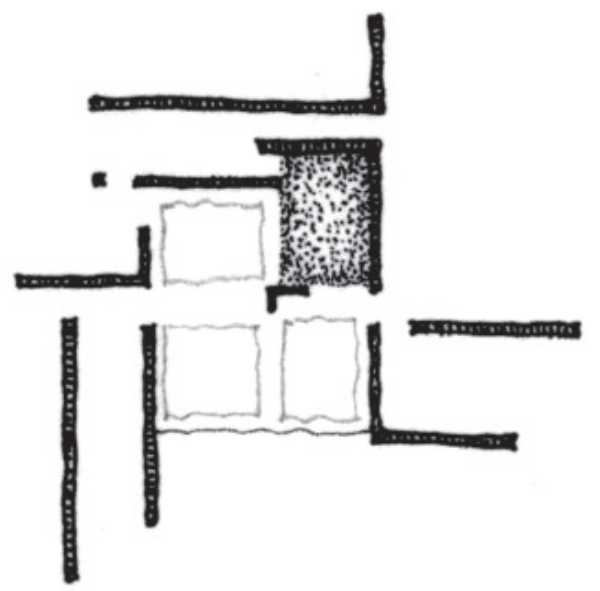

03 Incomunicación visual entre los distintos ámbitos vinculados al patio.

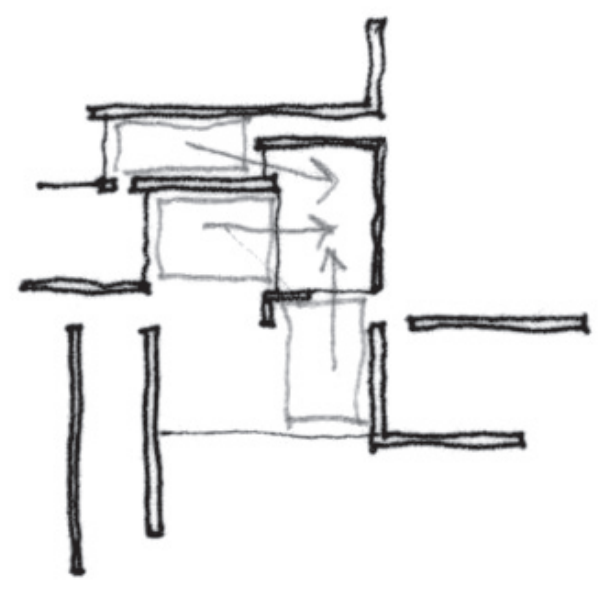

El patio, un vacío alrededor del que se condensa el espacio habitable a lo largo del tiempo, actúa como un dispositivo de transparencia fenomenológica ${ }^{11}$, articulando la percepción simultánea de espacios estratificados; une y distancia a la vez, revelando la complejidad intrínseca a la no-dualidad.

\section{LOS ELEMENTOS DEL PATIO}

En la secuencia de acceso a la casa, el patio solo se revela tras un sucesión de quiebros y vistas tangenciales que articulan lo que Fisac denomina «sistema de sorpresa» ${ }^{12}$ (Fig. 04). El paisaje interior del patio se compone cuidadosamente, pero se muestra aparentemente impensado, como si hubiese sido ya encontrado en el lugar $^{13}$. Un conjunto de rocas, un estanque y un árbol de hoja caduca emergiendo entre la hierba configuran la escena. A continuación se describen las percepciones que producen las características de cada uno de estos elementos en el habitante.

Se aprecia un paralelismo en el espacio, mostrando la variedad dentro de la unidad, ya que el mismo material se presenta con varios acabados en distintos elementos arquitectónicos. Las rocas muestran un aspecto tosco y natural, como si fueran una preexistencia respecto a la casa; la materia pétrea mantiene sus contornos irregulares cuando se concierta para formar los muros de mampostería que delimitan el salón, y se trabaja y apomaza para configurar el hogar de la chimenea (Fig. 05).

Redundando en el mismo efecto de paralelismo, se emplea un mecanismo opuesto; se produce la integra- ción de lo diverso al usar el mismo tono grisáceo de las rocas en el pavimento sintético. Así, de una superficie tersa y continua parecen emerger las rocas sin solución de continuidad (Fig. 06).

La composición orgánica que adoptan las piedras busca una apariencia fortuita; se disponen delimitando el estanque y, del otro lado del vidrio, vuelven a surgir en el salón, agolpándose al calor de la chimenea. De este modo, el interior y el exterior se intersecan, desdibujando el límite; lo natural y lo construido se superponen.

En el reflejo del estanque de bordes quebrados se produce la paradoja de poder contemplar el cielo mirando al suelo. Escrutando entre el reflejo, se puede atisbar la visión del fondo, y entre la masa de agua, descubrir los peces que lo habitan, tal y como referencia Arqués ${ }^{14}$. Éstos introducen el movimiento constante en la quietud del patio; observar su cadencioso deslizamiento, sus trayectorias aleatorias y cambiantes, induce la percepción de una letanía visual que embelesa la mente y predispone al ensimismamiento. Tal vez el embrujo se rompa con la aparición fugaz de la luz entre las penumbras del fondo cuando rebota inesperadamente sobre las escamas de un pez, o con la perturbación de la tersura de la superficie de agua, sea porque alguna hoja cae sobre ella o porque sus habitantes se aventuran a explorar el otro lado.

La impermanencia también se manifiesta en la vegetación presente en el patio. En la paulatina transformación que experimenta el árbol de hoja caduca que 

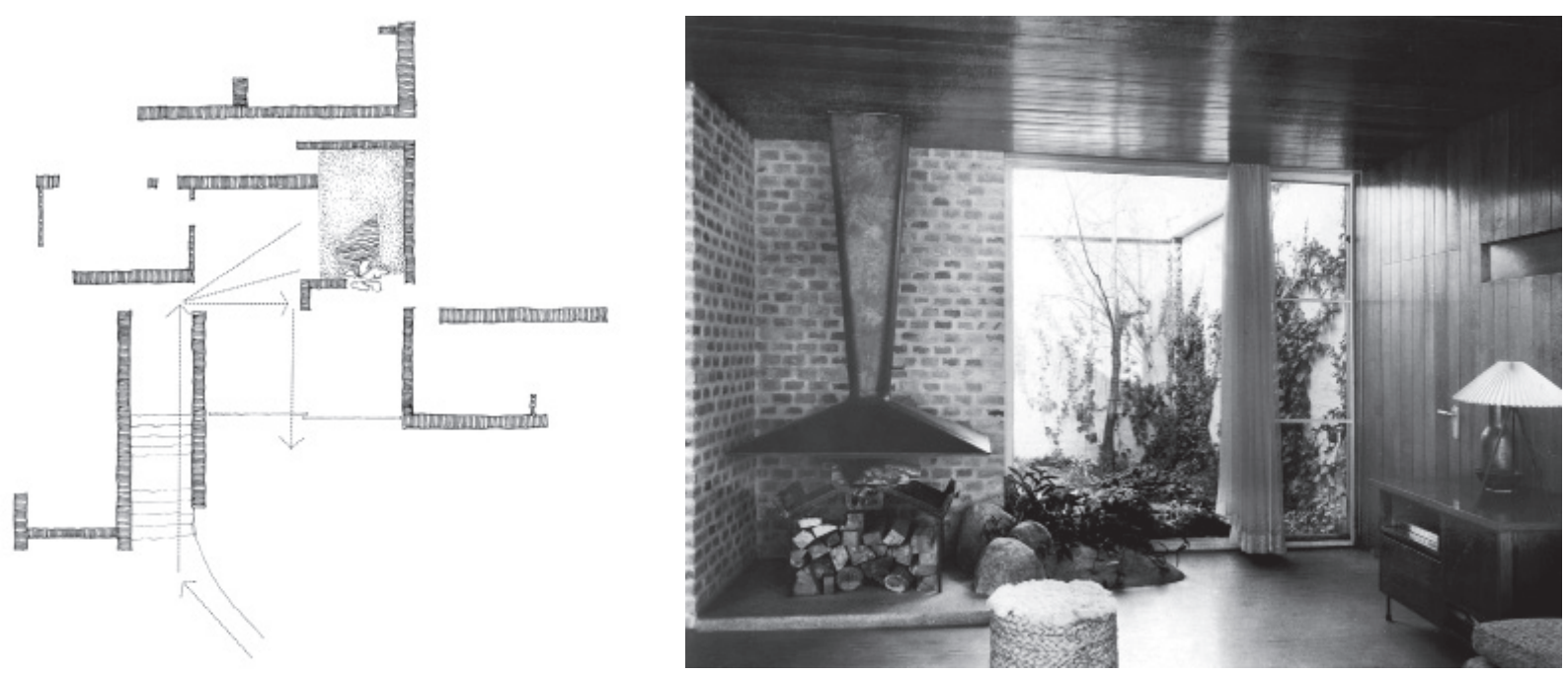

04 Secuencia de acceso

05 Visión del patio desde el estar en la primera época.

06 Material pétreo empleado con distintos acabados, y asociación perceptiva del pavimento con el conjunto de rocas a través del color.

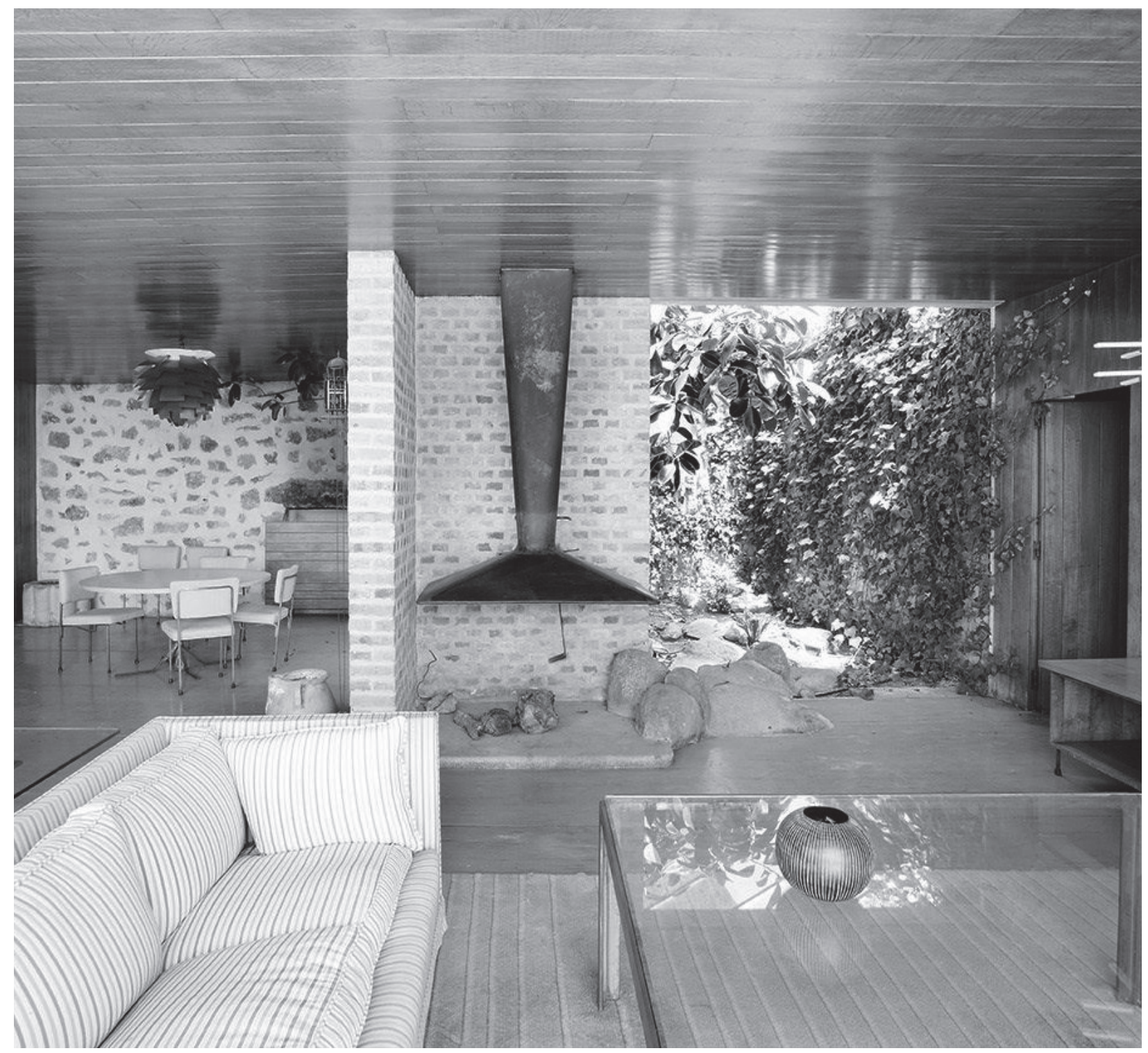



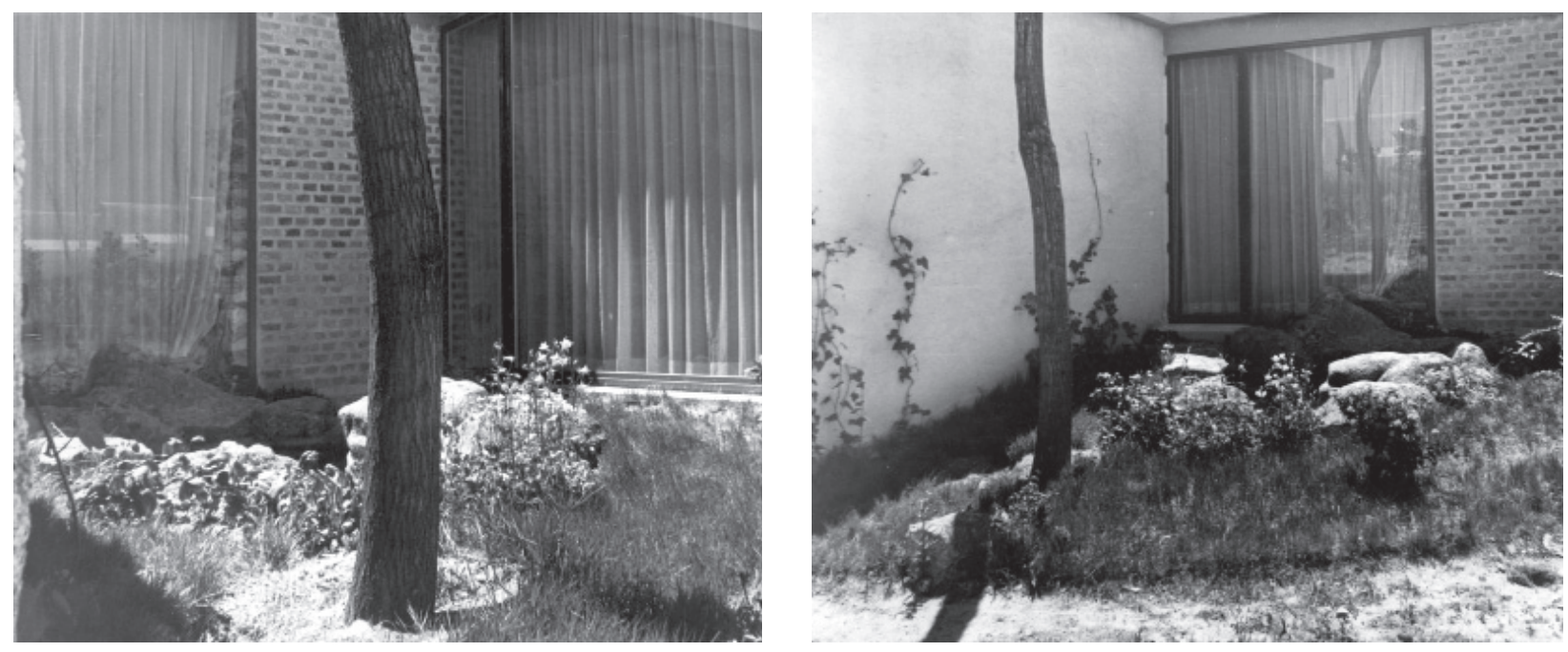

07 Árbol filiforme de hoja caduca en contraposición al conjunto de rocas que acota el estanque en la primera época.

crece entre el mullido manto de hierba, se manifiesta el inexorable paso del tiempo. Su esbelta verticalidad se contrapone a la horizontalidad de la composición de rocas y del estanque (Fig. 07).

El proceso de integración del patio en el interior culmina con su cubrición mediante un lucernario y la retirada de los paramentos de vidrio y las cortinas que los protegían. La operación exige la retirada del árbol caducifolio y conlleva la desaparición del tapiz de hierba. En su lugar, el suelo se vuelve más pedregoso y agreste, y entre sus grietas arraigan algunos helechos. La hiedra que colonizaba los muros del patio se desborda y comienza a avanzar por las paredes del estar. Un ficus crece al borde del comedor; cuando alcanza el lucernario, se ve obligado a arquearse, con unas ramas pendiendo hacia la esquina opuesta y otras adentrándose en el salón (Fig. 08).

La escena del paisaje interior abandona la claridad compositiva anterior para hacerse más compleja. La verticalidad del árbol desaparece y las curvas orgánicas dominan el patio, pero ésta todavía se evoca a través de la campana de la chimenea, que pende del techo pero parece elevarse hacia él, gracias a la sinuosidad de sus formas que recuerda a la elevación ingrávida y ondulante de la columna de humo que está destinada a recoger.

\section{ECOS TAOÍSTAS}

En los elementos que conforman el patio pueden rastrearse la presencia de los cuatro principios taoístas enunciados en la introducción: empatía, ritmo vital, reticencia y vacío.

La empatía se manifiesta, en primer lugar, a través de la resonancia entre distintos elementos; por un lado, por integración de lo diverso, asociando elementos diferentes como el pavimento sintético y las rocas mediante el empleo de una característica común: el tono. Por otro lado, se refuerza el descubrimiento de la variedad en la unidad usando materiales como la piedra, que de por sí se caracterizan por su heterogeneidad intrínseca, en distintos elementos arquitectónicos y acabados.

La resonancia alcanza un nivel más profundo en la composición del patio, que puede llegar a interpretarse como una metáfora de un paisaje ideal reproducido a una escala menor, como suele ser característico de los jardines japoneses tradicionales ${ }^{15}$. La hierba de la primera época puede así evocar una pradera de la que emergen montañas pétreas, entre las que se extiende un lago.

Contemplar las trayectorias hipnóticas de los peces que habitan ese lago puede conducir a la percepción de una letanía visual que, al abstraer la mente de todo pensamiento, ponga al habitante en resonancia con la escena observada.

La empatía también puede despertarse al evidenciar la no-dualidad mediante contrastes, revelando la esencia holística del universo al presentar simultáneamente lo opuesto e invitando de este modo al habitante a 


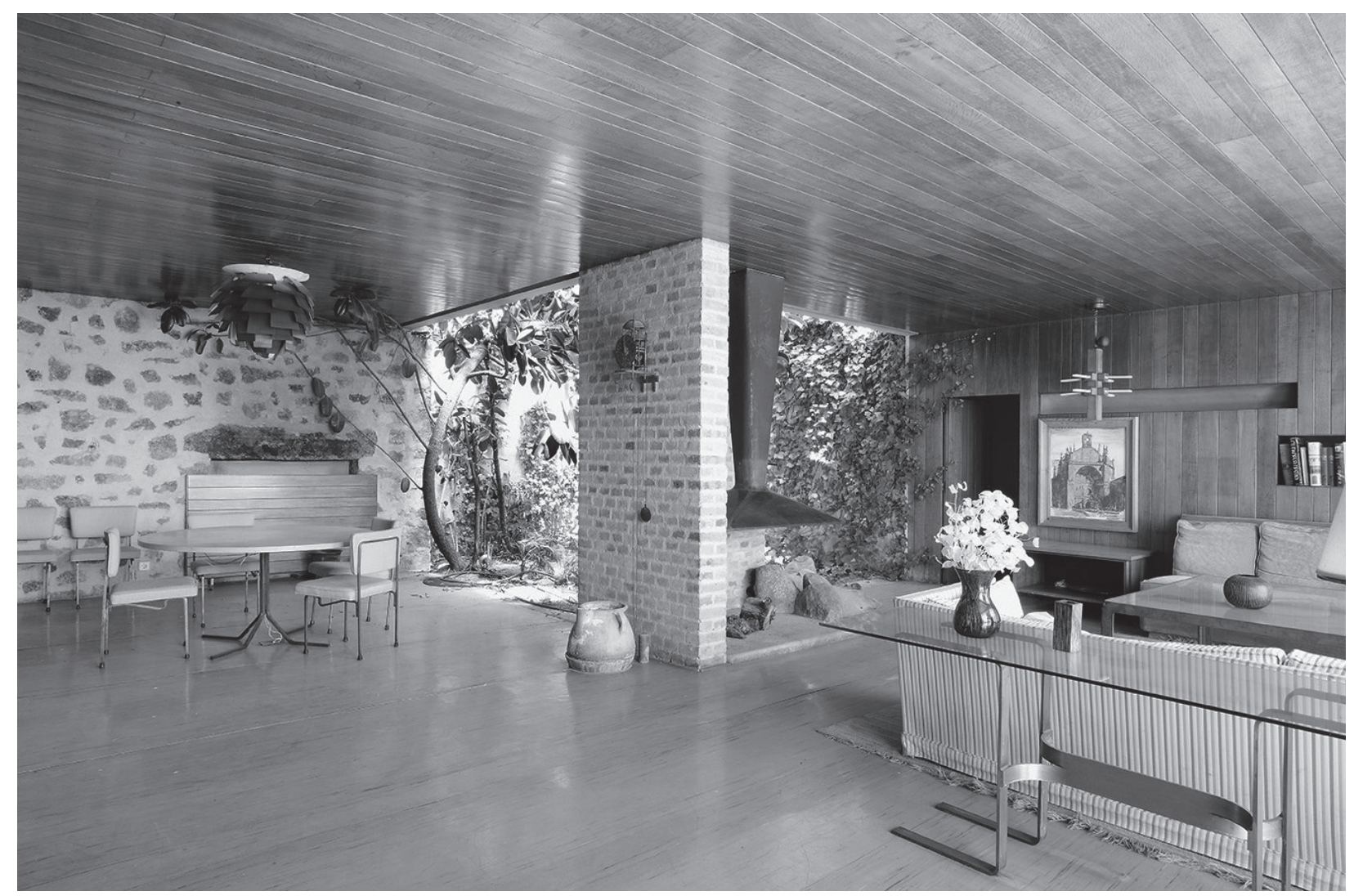

08 Visión del patio en la segunda época; el ficus se arquea al impedirse su desarrollo vertical.

09 Contraste entre lo curvo y lo recto, lo geométrico y lo orgánico.

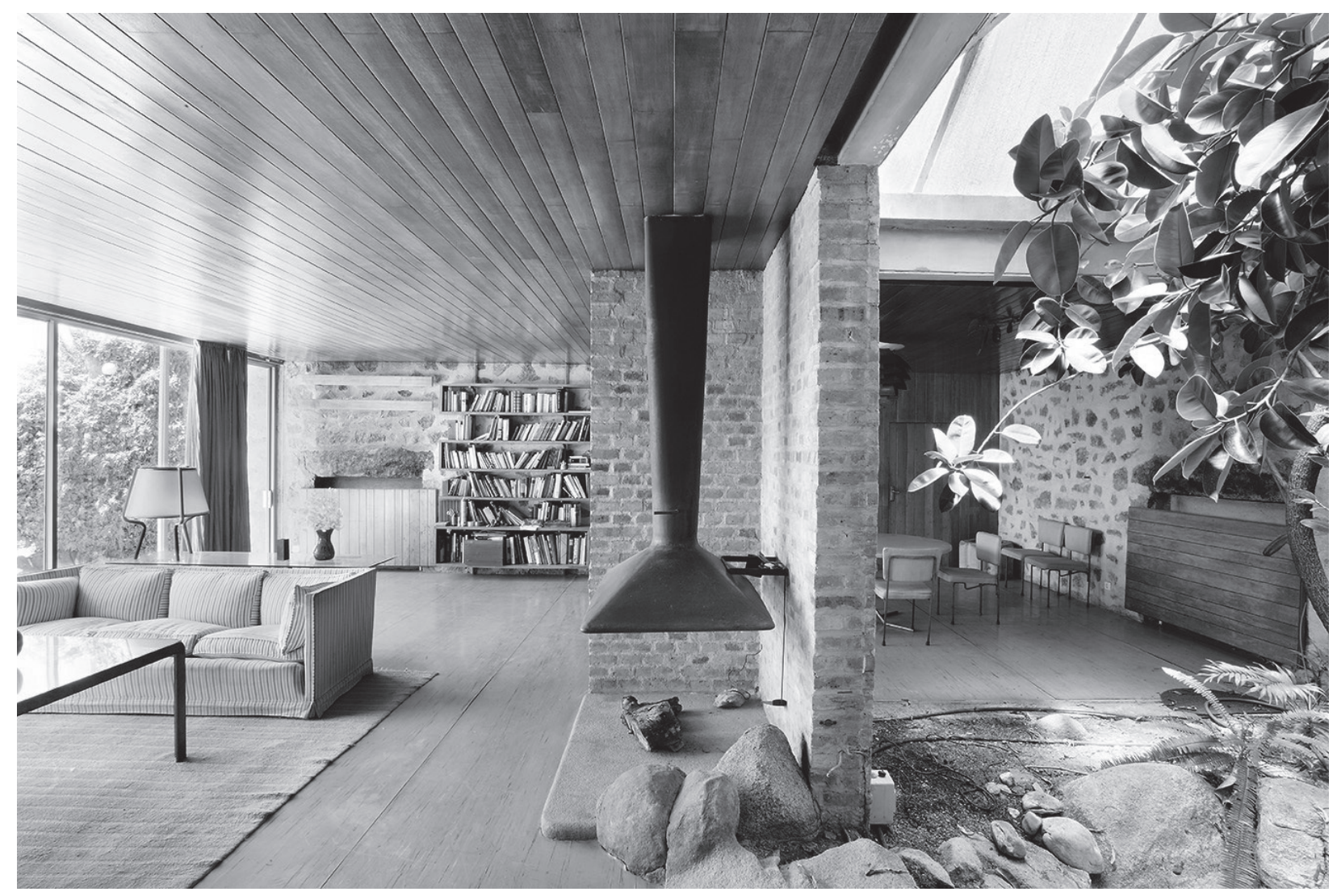


integrar la realidad. En el patio, se perciben las formas sinuosas y orgánicas de la vegetación, las rocas y el estanque en contraposición a la ortogonalidad de la arquitectura, mostrando a la vez lo curvo y lo recto, lo geométrico y lo orgánico; el ladrillo se pliega $90^{\circ}$ envolviendo la campana ondulante de la chimenea, mientras las redondeces de las piedras invaden el plano rectangular del hogar (Fig. 09). La horizontalidad de la composición de rocas y la superficie de agua se opone a la verticalidad del árbol y de la chimenea.

Observando el patio desde el estar, se puede encontrar en él la convergencia entre fuego y roca, aire y agua, las cuatro raíces que enuncia Empédocles como componentes primordiales de lo visible ${ }^{16}$. Junto a lo inerte, la vida, la vegetación y los peces; la naturaleza y el artificio de la arquitectura. El paisaje ideal, simbólico y acotado, se contrapone desde cualquiera de los ámbitos al paisaje real que se despliega frente a la casa, cambiante y extenso (Fig. 10).

El ritmo vital se manifiesta en el movimiento de los peces que nadan en el estanque, y en la primera época, en las transformaciones estacionales del árbol de hoja caduca. Cuando el patio se cubre, el lento crecimiento de la vegetación a lo largo del tiempo no permite la visualización tan inmediata del cambio constante; sin embargo, la tensión queda impresa en el ficus, cuya energía de crecimiento contenida por el lucernario le obliga a arquear sus ramas diagonalmente. También puede percibirse en rasgos menos evidentes, como el equilibrio complejo que adoptan las estancias respecto al patio, pautado por una cuidada asimetría armónica, o en fenómenos efímeros como pequeńos destellos de luz que pueden anidar en las sombras del estanque.

Tanto la no-dualidad como el ritmo vital se hacen presentes en la casa por medio de la reticencia, gestos sutiles y apenas esbozados. Por ejemplo, el refinado engarce espacial entre ámbitos sugiere la existencia de una estancia contigua, el cuarto de juegos, que no llega sin embargo a desvelarse. La ambigüedad espacial entre estar y patio desdibuja sus límites, ya que tanto las rocas como la vegetación de la segunda época invaden el interior, generando una intersección entre lo natural y lo construido. Más aún, cuando el patio se cubre se incorpora plenamente al estar y en verdad pasa a ser un espacio interior; sin embargo, la vegetación y el tratamiento pedregoso del suelo, junto con la luz cenital que lo baña, genera una percepción ambivalente que lo aproxima más a un exterior.

Otros mecanismos todavía más sutiles materializan la reticencia, como la paradoja de mirar al suelo del estanque para hallar el cielo, o encontrar lo inesperado al recorrer la secuencia espacial: cuando se accede al estar, no es sino tras alcanzar el plano plegado de ladrillo cuando se advierte el conjunto de rocas que sorpresivamente parecen haber huido del patio para alcanzar la chimenea.

El vacío se evidencia en el carácter no estancial del patio. Se produce una integración visual con el estar, pero se mantiene inaccesible físicamente; en la primera época son los paramentos de vidrio los que lo preservan del paso, pero incluso cuando éstos se retiran, la vegetación y la textura pedregosa e irregular del suelo lo mantienen escindido (Fig. 11). El patio sólo se habita con la mirada; un espacio creado para no estar, es la más profunda de las paradojas arquitectónicas, y el modo más intenso de materializar el concepto de vacío ${ }^{17}$.

\section{CONCLUSIONES}

Fisac, durante sus estancias orientales, se empapó de los conceptos taoístas que subyacen bajo su arquitectura tradicional. A lo largo del artículo ha podido observarse cómo materializaciones de los principios estéticos taoístas definidos por Racionero no solo pueden hallarse en su casa en Cerro del Aire, sino que determinan profundamente la configuración del patio, el espacio que la caracteriza con mayor intensidad ${ }^{18}$.

Todos estos mecanismos que beben de la fuente taoísta tienen como fin impresionar profundamente los sentidos y producir emoción en el habitante; éste se conmueve porque se siente concernido - aunque sea inconsciente o intuitivamente- por los fenómenos evidenciados: se reconoce en la esencia de lo contemplado como parte integral de la naturaleza, en el aliento del ritmo vital y en la inexorabilidad de la impermanencia.

En definitiva, Fisac emplea estas estrategias para lograr humanizar el trozo de aire que es la arquitectura; constituyen ese "no sé qué»" que él enuncia y que confiere alma al espacio. Desgranarlas permite aprender de las sabias intuiciones del maestro para tratar de trasladarlas a la práctica arquitectónica. 


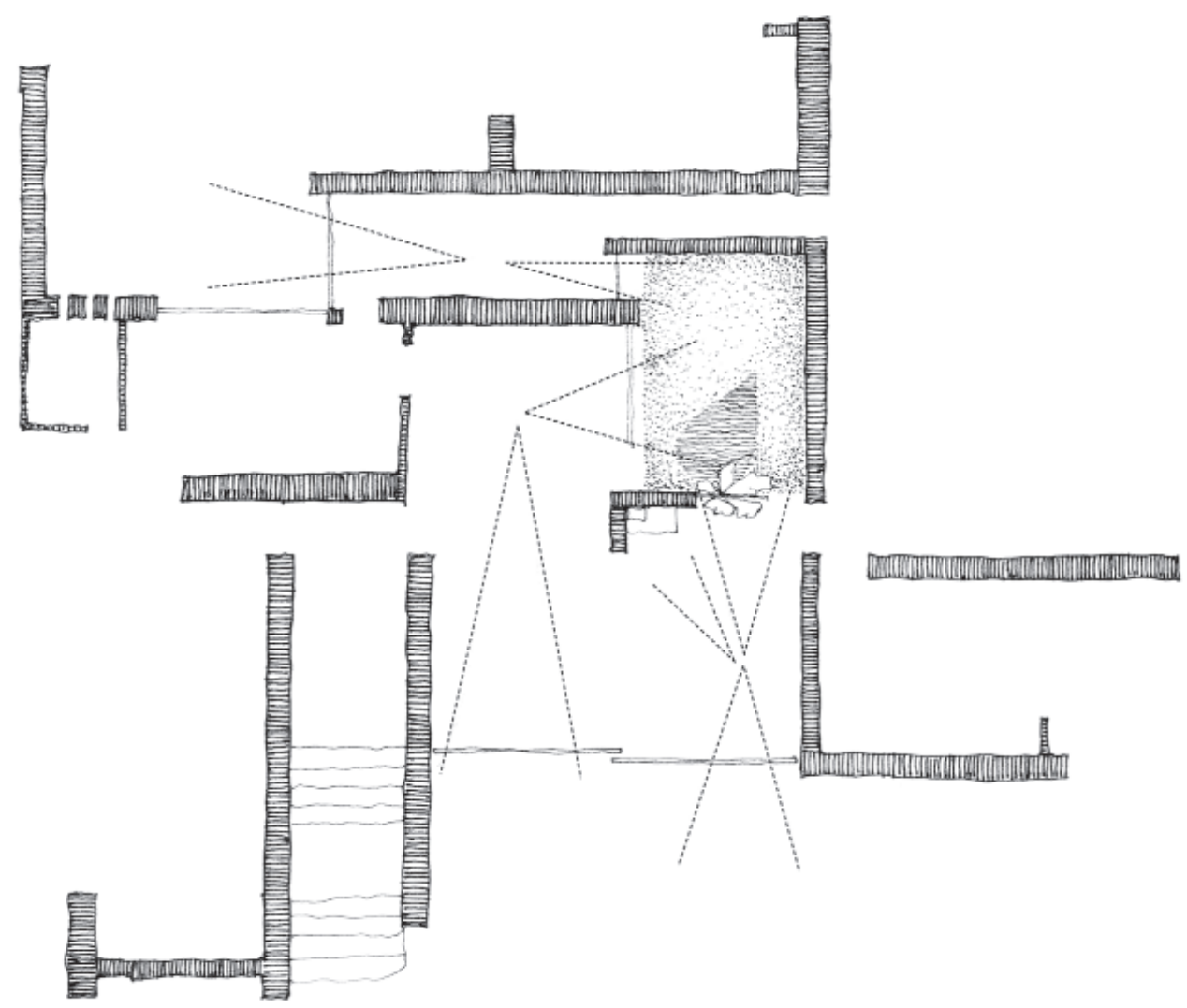

10 Visión simultánea de lo acotado y lo extenso desde el comedor y el estar.

11 Patio de contemplación.

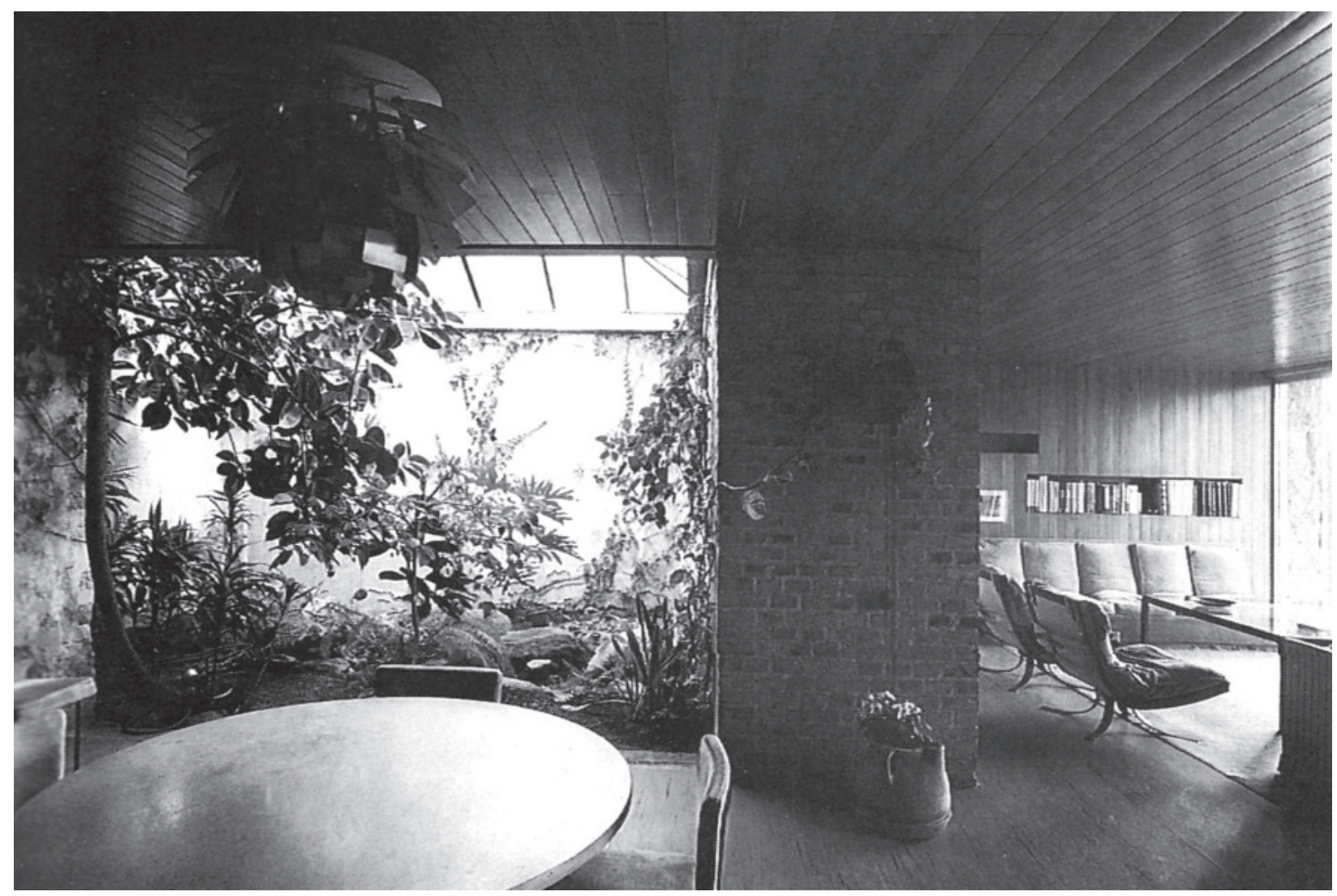




\section{Notas}

1. Cf. José María Fernández Isla, «Miguel Fisac, Vivienda en Cerro del Aire», Arquitectura 309 (1997): 61-63.

2. Cf. María Isabel Navarro Segura, «Miguel Fisac: 2003», Basa 27 (2002): 5-39; María Cruz Morales Saro, La arquitectura de Miguel Fisac (Ciudad Real: Colegio de Arquitectos de Ciudad Real, 1979); Francisco Arqués Soler, «La obra y el ornamento en la obra arquitectónica. El Centro de Estudios Hidrográficos de Miguel Fisac. Un para qué, un cómo y un no sé qué» (Tesis doctoral, Universidad Politécnica de Madrid, 2003).

3. Cf. Miguel Fisac Serna, Carta a mis sobrinos (Estudiantes de arquitectura) (Ciudad Real: Autor-Editor, 2010).

4. Óscar Lorente Ayala, «Hacia la esencia de la arquitectura: el papel de Oriente en los años experimentales de Fisac», Espacio, tiempo y forma. Serie VII, Historia del Arte 25 (2012): 395-418; Idem., «Miguel Fisac, un arquitecto español en Japón» (comunicación presentada en el I Congreso Internacional Itinerarios, viajes y contactos Japón-Europa, Valladolid, 7 de mayo, 2011).

5. Francisco Arqués Soler, «Miguel Fisac, (1913-2006): Un propósito experimental», Informes de la construcción 58-503 (2006): 7.

6. Un análisis de cómo ciertos conceptos de la arquitectura y jardinería japonesa se materializan en esta casa puede encontrarse en Sonia Vázquez-Díaz, «Patios del Silencio» (Tesis doctoral, Universidade da Coruña, 2013), 285-322.

7. Cf. Luis Racionero i Grau, Textos de estética taoísta (Madrid: Alianza, 1983), 35-57.

8. Cf. Salvador Pániker Alemany, Filosofia y mistica (Barcelona: Kairós, 2003), 13-14.

9. Sobre epistemología de la fenomenología hermenéutica, cf. David Seamon, «A Way of Seeing People and Place: Phenomenology in EnvironmentBehavior Research», en Seymour Wapner et al., eds. Theoretical Perspectives in Environment-Behavior Research (Nueva York: Plenum, 2000), 157-178.

10. Kauzo Okakura, El libro del té (Barcelona: Círculo de lectores, 2003), 85.

11. Cf. Colin Rowe y Robert Slutzky, "Transparency: Literal and Phenomenal", Perspecta 8 (1963): 45-54.

12. Miguel Fisac Serna, «Lo que he aprendido en la Alhambra», en Andrés Cánovas Alcaraz (ed.), Miguel Fisac, Medalla de Oro de la Arquitectura 1994 (Madrid: Ministerio de Fomento; CSAE, 1997), 11.

13. «En la arquitectura japonesa, [las] disposiciones topográficas externas, de explanadas, caminos y estanques, no solo se mantienen como naturales, sino que se fuerzan, con rocas, piedras, árboles, plantas y estanques, a que se hagan más rústicas, más agresivas, más salvajes» (Fisac, «Lo que he aprendido en la Alhambra», 10).

14. Cf. Arqués, «Miguel Fisac», 7.

15. Cf. Jiro Takei y Marc Keane, Sakuteiki. Visions of the Japanese Garden. A Modern Translation of Japan's Gardening Classic (Boston: Tuttle Publishing, 2001), 59.

16. Cf. Frederick Copleston, Historia de la Filosofía. Vol. 1. De la Grecia Antigua al Mundo Cristiano (Barcelona: Círculo de lectores, 2011 ), 57.

17. Cf. Fernando Espuelas Cid, El claro en el bosque: reflexiones sobre el vacio en arquitectura (Barcelona: Fundación Caja de Arquitectos, 1999).

18. Cf. Racionero, Textos de estética taoista, 35-57.

19. Cf. Francisco Arqués Soler, «Un para qué, un cómo y un no sé qué» (ponencia en el congreso Miguel Fisac - Huesos varios, Valladolid, 18 de enero al 28 de agosto, 2008). Con acceso el 30/11/2013, http://oa.upm.es/4219/

\section{Procedencia de las imágenes}

Fig. 01. Dibujos de la autora, basados en Andrés Cánovas Alcaraz, ed., Miguel Fisac, Medalla de Oro de la Arquitectura 1994 (Madrid: Ministerio de Fomento; CSAE, 1997): 11, y en José María Fernández Isla, «Miguel Fisac, Vivienda en Cerro del Aire», Arquitectura 309 (1997): 63.

Fig. 03, 04 y 10. Dibujos de la autora.

Fig. 02, 05 y 07. Archivo Fisac, Fundación Miguel Fisac.

Fig. 06, 08 y 09. Archivo DO.CO.MO.MO Ibérico, fotografías de José Hevia.

Fig. 11. Fotografía procedente de Francisco Arqués Soler, Miguel Fisac (Madrid: Pronaos, 1996): 109.

\section{Sobre los autores}

Sonia Vázquez-Díaz. Doctora Arquitecta y Máster en Urbanismo por la Escuela Técnica Superior de Arquitectura de A Coruńa. Autora de la tesis Patios del silencio, dirigida por el Prof. Dr. Miguel Ángel Alonso del Val y el Prof. Dr. Luis Suárez Mansilla, de la Universidad de Navarra, y calificada Cum Laude. Profesora de proyectos en el Departamento de Proyectos Arquitectónicos y Urbanismo de la Universidade da Coruña. Profesora invitada en el Máster en Diseńo Arquitectónico de la Pontificia Universidad Católica Madre y Maestra de la República Dominicana. Como arquitecta del Estudio Zara (INDITEX) construyó tiendas en 12 países, entre las que destaca la rehabilitación de los restos de la iglesia de San Antonio el Real en Salamanca.

sonia.vazquez.diaz@udc.es

Luis Suárez Mansilla. Arquitecto por la Escuela Técnica Superior de Arquitectura de la Universidad de Navarra (ETSAUN) donde se graduó en 1999 con el Premio Extraordinario Fin de Carrera. En 2003 obtuvo el Master in Design Studies en Harvard University Graduate School of Design y se incorporó a la docencia como profesor asociado del Departamento de Proyectos de la ETSAUN. Desde 2010 es Doctor Arquitecto Cum Laude por una tesis titulada Estrategias y Efectos de Escala. Dirige el estudio Suárez Santas Arquitectos, actividad que compagina con la docencia y la investigación teórica. Ha sido premiado en más de veinte concursos nacionales e internacionales y participado en distintas exposiciones como la muestra Jóvenes Arquitectos de Espańa (JAE) y la XI Bienal de Arquitectura de Venecia. En 2009 fue galardonado por The European Centre for Architecture con la distinción Europe 40 under 40 y en 2011 recibió el Premio Internacional de Arquitectura Bauwelt a la mejor opera prima.

Isuarezmansilla@gmail.com 